CUPAUAM. 17-1989, 45-65

\title{
POBLAMIENTO PRERROMANO Y RECINTOS CICLOPEOS DE LA SERENA, BADAJOZ
}

\author{
ALONSO RODRIGUEZ DiAZ \\ PABLO ORTIZ ROMERO
}

\section{Resumen}

El objetivo principal del presente trabajo es dar a conocer, dentro del marco general del poblamiento prerromano del Valle Medio del Guadiana, una primera valoración global de los trabajos arqueológicos realizados entre 1986 y 1988 en los recintos ciclópeos de La Serena (Badajoz). Dichos asentamientos fueron prospectados en su práctica totalidad durante los años 1985 y 1986, con vistas a la elaboración de las Cartas Arqueológicas de Castuera-Zalamea de la Serena y Don Benito. Los primeros resultados de estos trabajos de prospección pusieron enseguida de relieve las peculiaridades de esta comarca respecto al resto de la provincia badajocense, al comprobar la particular concentración en dicho espacio de diversos tipos de construcciones ciclópeas. Sin descartar la posibilidad de que los romanos hubieran construido algunos de estos recintos, la base teórica de nuestro Proyecto, inicialmente, contemplaba la posibilidad de un origen prerromano de los mismos en función de los resultados obtenidos, años antes, en yacimientos similares en el sureste de la provincia de Córdoba. A medida que hemos ido avanzando en su estudio, basado hasta ahora en nuevas prospecciones y sondeos estratigráficos, igualmente hemos ido perfilando aquella visión inicial y concretando nuestras actuales líneas de investigación. Estas, intentando conectar con los trabajos que paralelamente se desarrollan en otros lugares de la geografía peninsular, se centran en la distinción de rasgos y variables sobre la función, filiación cultural y cronología de estos edificios.

\section{Résumé}

L'objet de ce travail consiste à evaluer, dans le cadre géneral des peuples pré-romaines de la Moyenne Vallée du Guadiana, les travails archéologiques réalisés de 1986 á 1988 aux enceintes cyclopéenes de La Serena (Badajoz). Ces établissements sont connus depuis 1985 en raison de l'élaboration des Cartes et Archéologiques de Castuera-Zalamea de la Serena et Don Benito. Sans oublier la possibilité de quelques constructions furent romaines, notre Project initial considerait la possibilité d'une origine pré-romaine des mêmes en relation aux résultats obtenus antérieurement à la province de Córdoba. Actuellement, après de nouvelles prospections et sondages stratigraphiques, nous avons profilé celle-là vision et notres lignes d'investigation prétendent evaluer des traits et variables au sujet de la fonction, filiation culturale et chronologie de ces bâtiments. 


\section{LA COMARCA Y EL POBLAMIENTO PRERROMANO}

Desde el punto de vista geográfico, La Serena se configura como una de las comarcas mejor definidas de la región extremeña (Terán y Solé Sabarís, 1968: 178). Como es sabido, ocupa la zona nordoriental de la provincia de Badajoz y sus límites principales son las Vegas Altas del Guadiana y la llamada Siberia Extremeña, al Norte; las sierras de Hornachos y Pedroso, al Sur; el valle del Matachel, al Oeste; y las comarcas de La Alcudia (Ciudad Real) y Los Pedroches (Córdoba), al Este. El soporte geológico de La Serena se corresponde con tres formas de relieve perfectamente diferenciadas entre sí: l) la penillanura de pizarras cámbricas y silúricas del nordeste, a veces asociadas a cuarcitas, que ofrece en los llamados "dientes de perro" uno de los rasgos más típicos del paisaje de esta zona; 2) el gran batolito que aflora en el entorno de Quintana de la Serena generando un panorama de perfiles suaves y redondeados con abundantes bloques de granito, resultado de una erosión diferencial; y 3) la serie de escarpadas sierras que se eleva sobre el llano de la comarca (AA.VV., 1968; Hernándo Fernández, 1971; Alvarez Muñoz, 1983). Todo ello se traduce en un paisaje árido, a veces agreste, de tradición y vocación eminentemente ganaderas y, en general, poco apto para la agricultura salvo en las vegas de los principales ríos y arroyos. Esta pobreza del suelo de La Serena contrasta con las enormes posibilidades minero-metalúrgicas del subsuelo, que se concretan en los abundantes filones de galenas argentíferas que salpican la zona (Somoza de la Peña, 1875; Guerra, 1972 y 1975; AA.VV., 1987). En cuanto a la hidrografía, resultan de referencia obligada los cursos del Guadámez, Guadalefra, Ortigas y, sobre todo, el Zújar. En su conjunto, constituyen las principales arterias de comunicación de esta comarca con el resto de las regiones que la circundan y muy particularmente con la Meseta Sur y la Alta Andalucía (Fig. 1).

Este marco geográfico ha constituido el medio natural de un interesante conjunto de culturas pre y protohistóricas hasta hace poco prácticamente desconocidas. Aparte de las cada vez más numerosas evidencias del poblamiento calcolítico (Jiménez Navarro y otros, 1950; Ortiz Romero, 1985) y diversos hallazgos atribuibles a la Edad del Bronce (1), particular importancia poseen en esta comarca los testimonios arqueológicos que se inscriben en el marco del ler milenio a. C. En este sentido, las muestras posiblemente más emblemáticas se encuentran en las estelas del Bronce Final (Almagro Basch, 1966; Almagro Gorbea, 1977; Bendala Galán, 1977; Celestino Pérez, 1985 y 1990; Barceló, 1989), cuya diversidad tipológica y complejidad conceptual se ponen de relieve en piezas como las de Capilla, Magacela, Benquerencia, Zarza Capilla, Cabeza del Buey (Almagro Gorbea, 1977; Enríquez Navascués, 1982; Enríquez Navascués y Celestino Pérez, 1984; Bueno Ramírez y otros, 1984), etc. Pero es el Período Orientalizante la etapa cultural de la protohistoria extremeña que mejor está representada en La Serena, auténtico hinterland de Medellín (Almagro Gorbea, 1977: 287-482) y marco real del Palacio-Santuario de Cancho Roano (Maluquer de Motes, 1981 y 1983; Maluquer de Motes y otros, 1986). En su conjunto, estos hallazgos ponen claramente de manifiesto el carácter abierto y dinámico de esta comarca ante los grandes acontecimientos culturales que se desarrollaron durante la primera mitad del Ier milenio a. C. en el cuadrante suroccidental de la Península y, al mismo tiempo, la convierten en uno de los accesos principales de dichas innovaciones a la región extremeña.

(1) Nos referimos a algunos enterramientos en cista aparecidos, hace ya algunos años, en las proximidades de Magacela. 


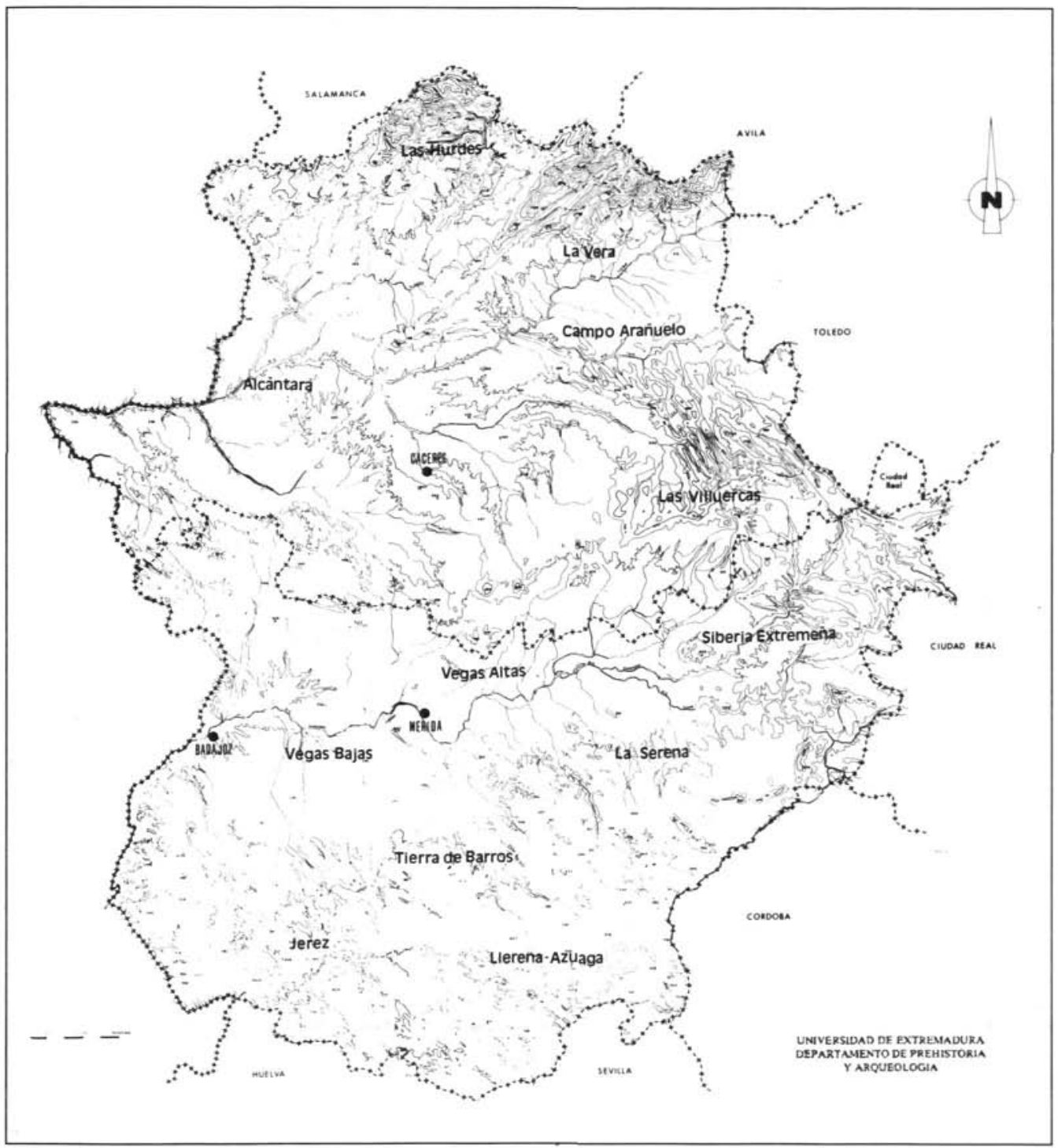

Figura 1. Principales comarcas naturales extremeñas.

A partir de este momento y hasta la Romanización, se abría uno de los vacíos culturales principales, no sólo de esta zona sino de toda la Baja Extremadura. Dicho período, la Segunda Edad del Hierro, era conocido únicamente a través de hallazgos aislados de muy diversa naturaleza (Almagro Gorbea, 1977: 507-509; Almagro Gorbea y Del Amo, 1985; Fernández Avilés, 1958, etc.) y algunas referencias de autores clásicos (Plinio, C.: NH. III, 13-15. En García y Bellido, 1947; Estrabon: Geografia. 1, 6. En García y Bellido, 1945; García Iglesias, 1971). Sin embargo, 
una intensa actividad de campo, basada esencialmente en prospecciones y excavaciones arqueológicas, nos ha permitido aproximarnos a la gran diversidad tipológica y cultural que caracteriza el poblamiento en nuestra región, entre el siglo IV a. C. y el cambio de Era (Rodríguez Díaz, 1987 y 1989). En el caso concreto de La Serena, dicha diversidad del poblamiento podría resumirse provisionalmente en los siguientes grupos y asociaciones de asehtamientos: pobladosnecrópolis, posibles asentamientos en el llano y peñones fortificados (fortines) relacionados con los poblados de mayor entidad y, por último, recintos ciclópeos de diverso tipo.

\section{I.1. Poblados, necrópolis, fortines y posibles asentamientos en el llano}

Consideramos como tales aquellos núcleos fortificados de extensión variable (desde 0,5 hasta $7 \mathrm{Ha}$., aproximadamente), situados -en la mayor parte de los casos- sobre elevaciones aisladas, próximas a un arroyo o río de caudal permanente, desde las cuales se domina ampliamente el terreno circundante. Son lugares fácilmente defendibles, de perfil amesetado, cuya estructura arquitectónica está configurada básicamente por un sistema de defensa y un desarrollo urbanístico más o menos complejo. En conjunto, se trata de un tipo de hábitat escasamente conocido en La Serena y la mayor concentración de asentamientos se observa precisamente en los límites de esta comarca y, de una forma más concreta, en el valle del Zújar. Entrerríos (Almagro Gorbea y Lorrio Alvarado, 1986), Castillo de Magacela, El Casarón de La Coronada, Embalse del Zújar (Castuera), Los Vadillos de Esparragosa de Lares, Cerro de las Poyatas de Zarza Capilla, Tabla de las Cañas (2) (Olmos Romera, 1978), Peñón del Pez (García Galán, 1984; Vaquerizo Gil, 1986; Rodríguez Díaz, 1987: 295-301) y El Cabezo de Capilla (3) son los ejemplos más conocidos que jalonan este curso fluvial, posiblemente una de las principales rutas de acceso a esta comarca desde la Alta Andalucía. De menor entidad, aunque no por ello sin interés, son los poblados de Terciomalillo de Campanario y El Colmenar de Castuera (Ortiz Romero, 1985), ambos en el cauce del Guadalefra, afluente del Zújar (Fig. 2).

Si desconocidos resultan los poblados prerromanos de La Serena, mucho más lo son sus necrópolis. En este sentido, únicamente referirnos a las posibles estructuras tumulares de planta cuadrada prospectadas por nosotros mismos en las proximidades del Peñón del Pez y al hallazgo casual en Los Vadillos de una posible necrópolis de incineración. Este último hallazgo, según información de D. Antonio Galán Martín, consistió en una sepultura de cremación en urna, localizada en un hoyo excavado en la roca y protegida por algunas piedras. Próximas a la urna, que contenía restos de huesos calcinados y cenizas, se encontraron como único ajuar una fíbula anular y una fusayola. Pudimos comprobar que la urna era de borde exvasado, hombro suavemente marcado, perfil globular y base cóncava de pie indicado. Tipológicamente se encuentra muy próxima a las recientemente documentadas, en un contexto de transición entre finales del siglo III a. C. y el cambio de Era, en la necrópolis de Hornachuelos de Ribera del Fresno (Rodríguez Díaz y Jiménez Avila, 1987-1988). En lo referente al ajuar, destaca la fíbula anular, de hierro, que tipológicamente se corresponde con las fíbulas de timbal del tipo " $2 \mathrm{e}$ " de Cuadrado (1957), característico del sur y Levante peninsular y cuya cronología en El Cigarralejo es del

(2) Excavaciones dirigidas por Dña. Coronada Domínguez de la Concha.

(3) Se encuentra en prensa la Memoria de los trabajos realizados dentro del Plan de la Serena en este lugar, bajo la dirección de los doctores Pastor y Sánchez Abal. 


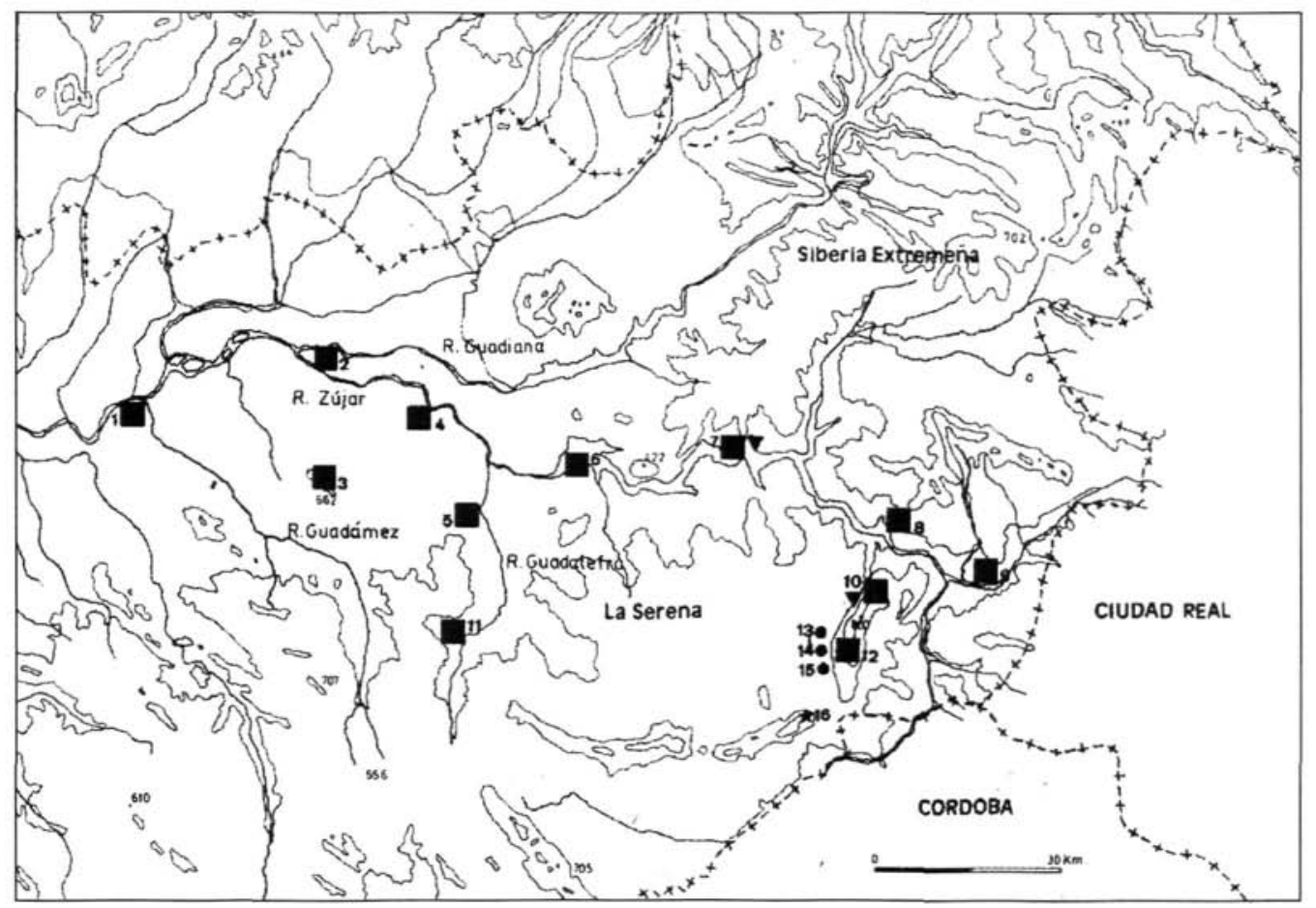

Figura 2. Poblamiento del Valle del Zújar. Póblados: 1, Medellín; 2, Entrerríos; 3, Castillo de Magacela; 4, El Casarón de La Coronada; 5, Terciomalillo (Campanario); 6, Embalse del Zújar (Castuera); 7, Los Vadillos de Esparragosa de Lares; 8, Tabla de las Cañas; 9, El Cabezo de Miróbriga; 10, Peńón del Pez (Capilla); 11, Las Poyatas de Zarza Capilla; 12, El Colmenar de Guadalefra (Castuera). Posibles asentamientos en el llano: 13 15: Los Tejares, La Cañada y El Negrizal (Zarza Capilla). Peñones fortificados: 16: La Cabezuela de Cabeza del Buey.

siglo IV a. C. La fusayola es de perfil troncocónico; está realizada con una arcilla semidepurada de color oscuro y no posee ningún motivo decorativo (Fig. 3).

En relación con los poblados de mayores proporciones, hemos de referirnos a una serie de pequeños peñones fortificados o fortines que visualmente están conectados entre sí y que posiblemente constituyeron un importante complemento de la estructura defensiva de los poblados en un momento aún no determinado de su evolución. Se trata de pequeños afloramientos protegidos por un número de recintos amurallados que oscila entre uno y tres y que se desarrollan, en disposición concéntrica, desde la cima hasta la base de la elevación. Dichos recintos se adaptan a los desniveles del terreno y siempre generan plantas muy irregulares. El ejemplo más representativo de los conocidos probablemente sea el de La Cabezuela de Cabeza del Buey, asociado al poblado de Las Poyatas (Rodríguez Díaz, 1987). A este mismo lugar, posiblemente se asocien también una serie de asentamientos en el llano, relacionados quizá con explotaciones agrícolas (Gil-Mascarell, 1971; Ruiz Rodríguez, 1978; Ruiz Rodríguez y otros, 1984; Blasco Bosqued y Alonso Sánchez, 1985), estudiada de forma aislada por Vaquerizo Gil (1984). Se trata de la Cañada del Negrizal, Las Marismas y Los Tejares. 


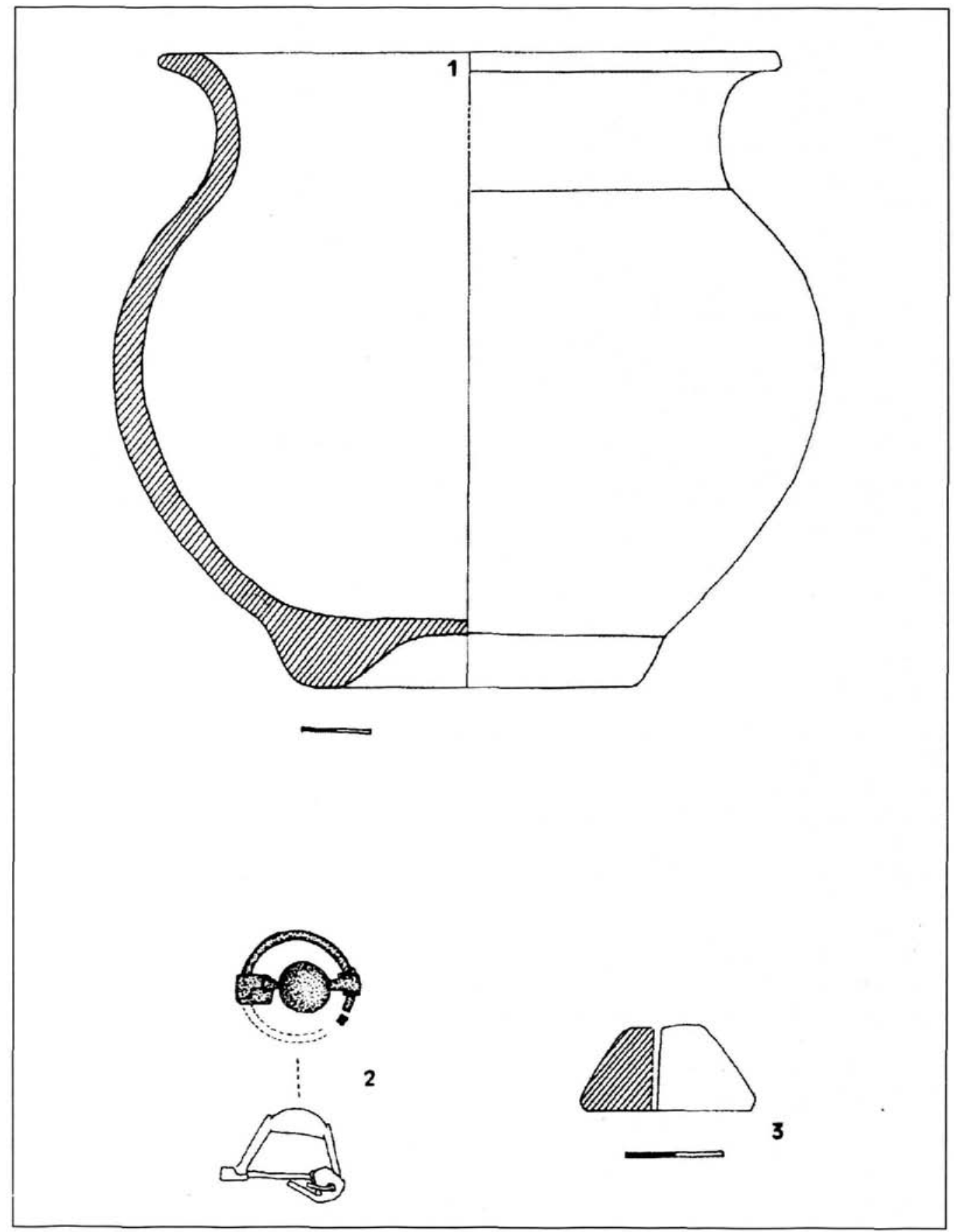

Figura 3. Ajuar de la sepultura de Los Vadillos (Esparragosa de Lares). 
Desde una perspectiva cronológico-cultural y básicamente a partir de una información de superficie, todos estos asentamientos parecen situarse entre el siglo IV a. C. y época altoimperial romana. En muy contadas ocasiones, se vislumbran elementos que pudieran conectar con épocas anteriores, por otra parte tan bien conocidas en yacimientos como Medellín y Cancho Roano. Estratigráficamente, parecen suponer una clara ruptura respecto al tipo de hábitat del Bronce Final-Período Orientalizante; ruptura que también parece confirmarse en el plano cultural, en virtud de la presencia en esta zona de no pocos elementos materiales y linguísticos de clara filiación meseteña (Almagro Gorbea y Lorrio Alvarado, 1987; Rodríguez Díaz, 1990). Sin embargo, son todos ellos aspectos que lógicamente necesitan del respaldo estratigráfico del que hoy carecemos.

\section{I.2. Fortificaciones y recintos ciclópeos}

Son precisamente estos asentamientos los que registran una mayor concentración en las tierras interiores de la comarca de La Serena y, en definitiva, particularizan el paisaje arqueológico de la mitad oriental de la provincia badajocense. Aunque en la mayor parte de los casos dichos recintos parecen responder a funciones de control comercial e incluso militar de extensas áreas y caminos naturales, su situación geográfica y su propia estructura nos han permitido considerar algunas variantes entre ellos. Así, hemos distinguido entre fortificaciones, recintos de altura y recintos-torre o recintos del llano.

\section{a) Fortificaciones y recintos de altura}

Estos últimos son construcciones con un marcado carácter defensivo al encontrarse situados en las cimas de escarpadas elevaciones -aisladas o no-, desde las cuales se domina con facilidad el entomo. Su estructura suele responder a una planta más o menos regular, configurada por uno o más recintos a veces concéntricos. Dichas construcciones, de tendencia rectangular o cuadrangular, se adaptan a las enormes irregularidades del terreno. El aparejo empleado en la construcción de estas estructuras consiste siempre en bloques ciclópeos, desbastados al menos en dos de sus caras. Éstos están dispuestos en seco, unidos por pellas de barro o acuñados con piedras de menor tamaño. La superficie media de los recintos de altura rara vez rebasa los $400 \mathrm{~m}^{2}$. Suelen mantener relaciones de intervisibilidad y no se asocian, por lo general, a los poblados.

Posiblemente, a partir del desarrollo de estos recintos surgieron las que denominamos fortificaciones, que presentan idénticas características constructivas y topográficas, pero de estructura más extensa e irregular. Ésta, en síntesis, consiste en un recinto de proporciones variables, localizado en una situación dominante y protegido a distintos niveles por otras contrucciones defensivas, de trazo rectilíneo, que suelen aprovechar los grandes afloramientos rocosos en su recorrido. Sin duda, ejemplos claros de estas fortificaciones los constituyen Las Merchanas de Don Benito y El Castillejo del Carrizal de Peraleda del Zaucejo (Fig. 4).

En su conjunto, fortificaciones y recintos de altura conforman una red de control sobre dos de las principales rutas naturales de La Serena: el valle del Guadámez y el camino hacia Almadén. Entre los recintos más sobresalientes que jalonan la primera de estas rutas se encuentran los de Cabeza Redonda, Castildavid, Las Merchanas, Castillejo del Moro, Cantalgallo y Valdegamas (Suárez de Venegas, 1990); por su parte, los enclaves de Las Pozatas, Los Pinos y Puerto Mejará (Ortiz Romero, 1985), entre otros, controlan la ruta hacia Ciudad Real.

Aparte de los restos arquitectónicos, los únicos elementos con que contamos para fechar estas construcciones son los casi siempre escasos fragmentos cerámicos recogidos en diversas 


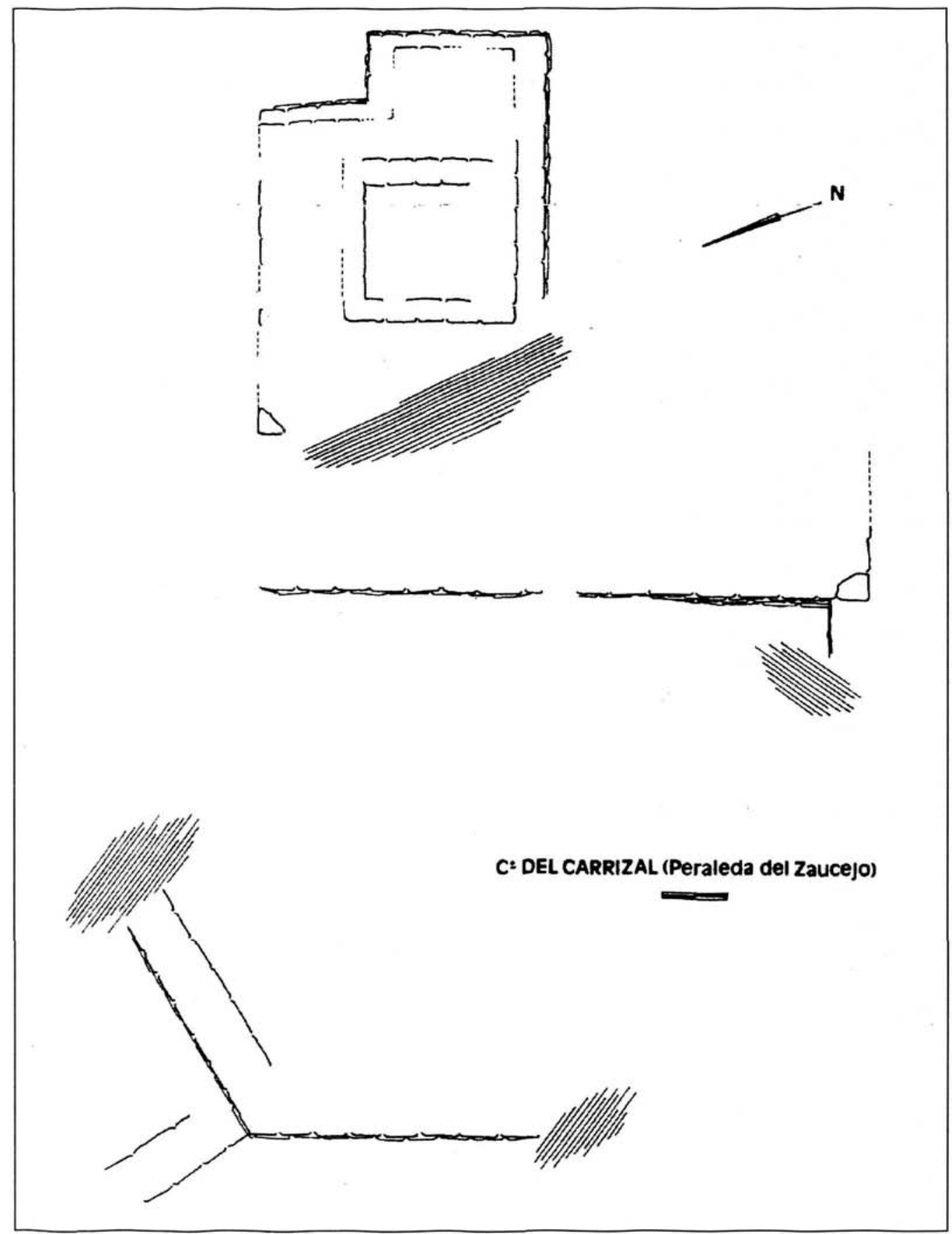

Figura 4. Planta-croquis de la fortificación del Castillejos del Carrizal (Peraleda del Zaucejo). 


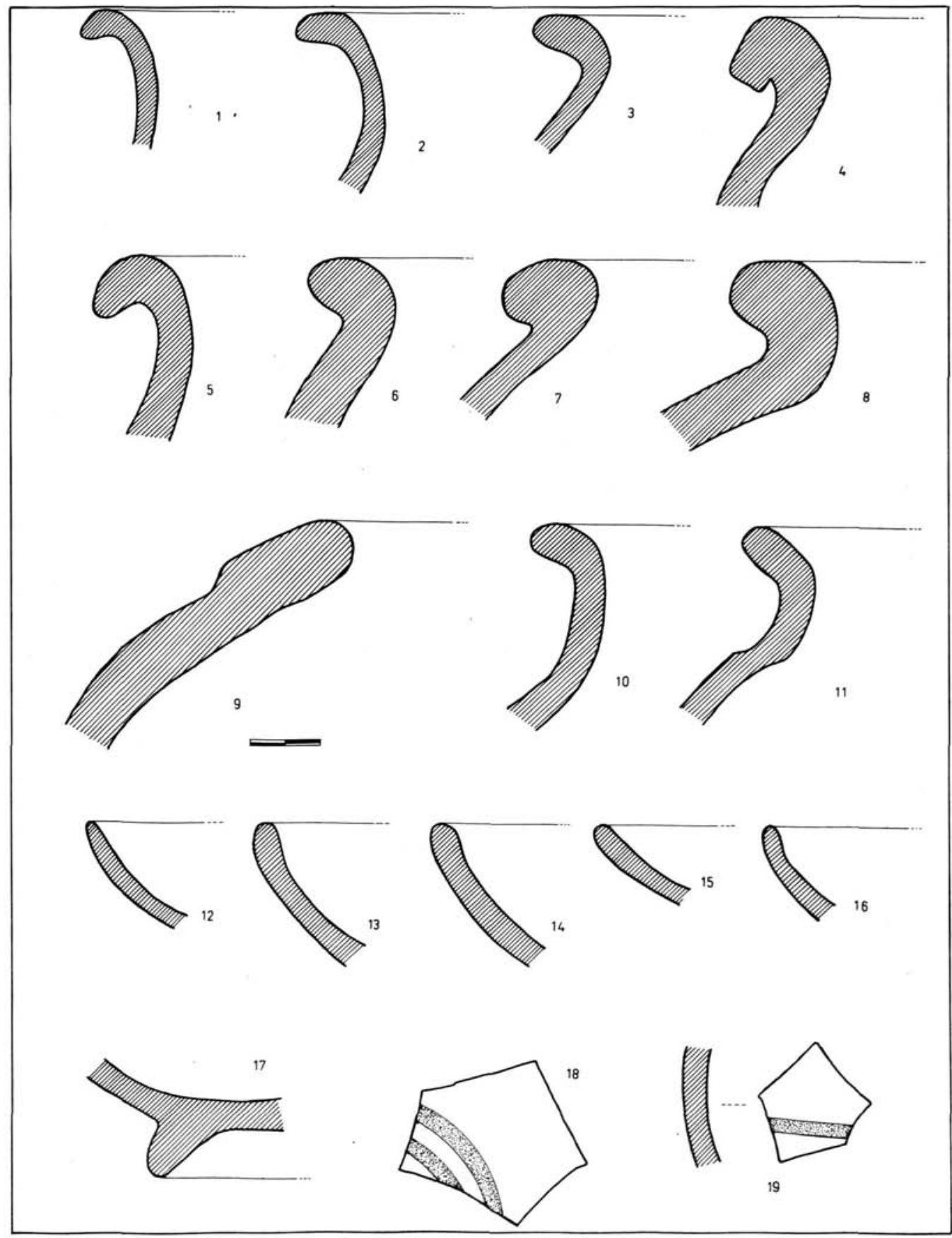

Figura 5. Materiales de superficie de diversos recintos de altura. 
prospecciones de superficie. En este apartado, sin duda, los tipos más significativos son aquellos cuya tipología es en buena parte deudora de la tradición indígena. Es el caso de ciertas urnas y vasijas de almacén con resabios ibero-púnicos y diversos fragmentos de cerámicas pintadas y grises (Ortiz Romero, 1990). Junto a dichos materiales, se encuentran las formas más conocidas de la cerámica común romana: cuencos, ollas, morteros, etc. (Fig. 5). Por tanto, resulta evidente que fortificaciones y recintos de altura fueron ocupados o reocupados durante época romana y su fecha inicial necesariamente está supeditada a la realización de sondeos estratigráficos. Morfológicamente, es el grupo de asentamientos que mayores semejanzas posee con los recintos de la Bética estudiados por Fortea y Bemier, identificados con las "torres de Aníbal" de los textos clásicos y fechados entre los siglos IV y III a. C. (Fortea y Bernier, 1970: 136-138). Sabido es que dichos planteamientos están siendo objeto de revisiones recientes a la luz de las investigaciones que A. Ruiz y 0. Arteaga llevan a cabo en la Campiña de Jaén (Ruiz Rodríguez, 1984; Ruiz Rodríguez y otros, 1987) y en la ciudad de Obulco (Arteaga, 1987), respectivamente.

\section{b) Recintos-torre}

Aunque prácticamente idénticos en organización y estructura a los recintos de altura y fortificaciones, los recintos-torre presentan un rasgo diferenciador esencial respecto a aquéllos: su localización en el llano. Dichas construcciones suelen situarse sobre suaves ondulaciones del terreno o tímidos afloramientos graníticos que particularizan el paisaje de la zona. Por lo general, se localizan próximos a las vegas de los ríos y arroyos de las tierras interiores de La Serena (Fig. 6). Como señalamos anteriormente, la estructura de estas construcciones suele responder a plantas regulares, de tendencia rectangular e incluso trapezoidal, con uno o más recintos realizados con aparejo ciclópeo. Su extensión media oscila entre los 300 y $400 \mathrm{~m}^{2}$ s según los casos. En contadas ocasiones, están próximos a algún poblado y mantienen entre sí relaciones visuales. En este sentido, referir como ejemplo más ilustrativo las torres de Los Caños, Cerro Porra, Torruco y Cerro de la Horca, todas ellas muy próximas al poblado de Magacela. La adopción del término "torre" para referirnos a esta variante de construcción ciclópea se debe fundamentalmente a razones de toponimia, ya que resulta muy frecuente encontrarnos vocablos como "Torruco", "Torruquillo", "Torrecilla", "Torreón", "Torrucha", etc. relacionados con los lugares donde se registra este tipo de hábitat.

En cuanto a la distribución de estos recintos-torre, destacar que la mayor concentración de hallazgos -en número de treinta y dos- se constata en la zona situada "entre Zalamea y Quintana de la Serena, en torno al asentamiento de Cancho Roano" (Ortiz Romero, 1985: 351), jalonando en buena parte el cauce del Ortigas hacia Medellin. Asímismo, nos encontramos algunos recintos de este tipo próximos al Guadalefra y al Zújar, ambos caminos naturales de reconocida importancia durante época protohistórica. Muy alejado de esta zona y como punto aislado, se encuentra el Torreón de Oliva de la Frontera (Rodríguez Díaz, 1987: 524-525), cuya relación con este núcleo de La Serena no deja de ser hoy por hoy una incógnita, debido a la ausencia de materiales que nos permitan aproximarnos a su adscripción cronológico-cultural. En este sentido, las construcciones de La Serena han sido objeto de diversos trabajos arqueológicos, cuyos resultados analizaremos muy resumidamente a continuación. 


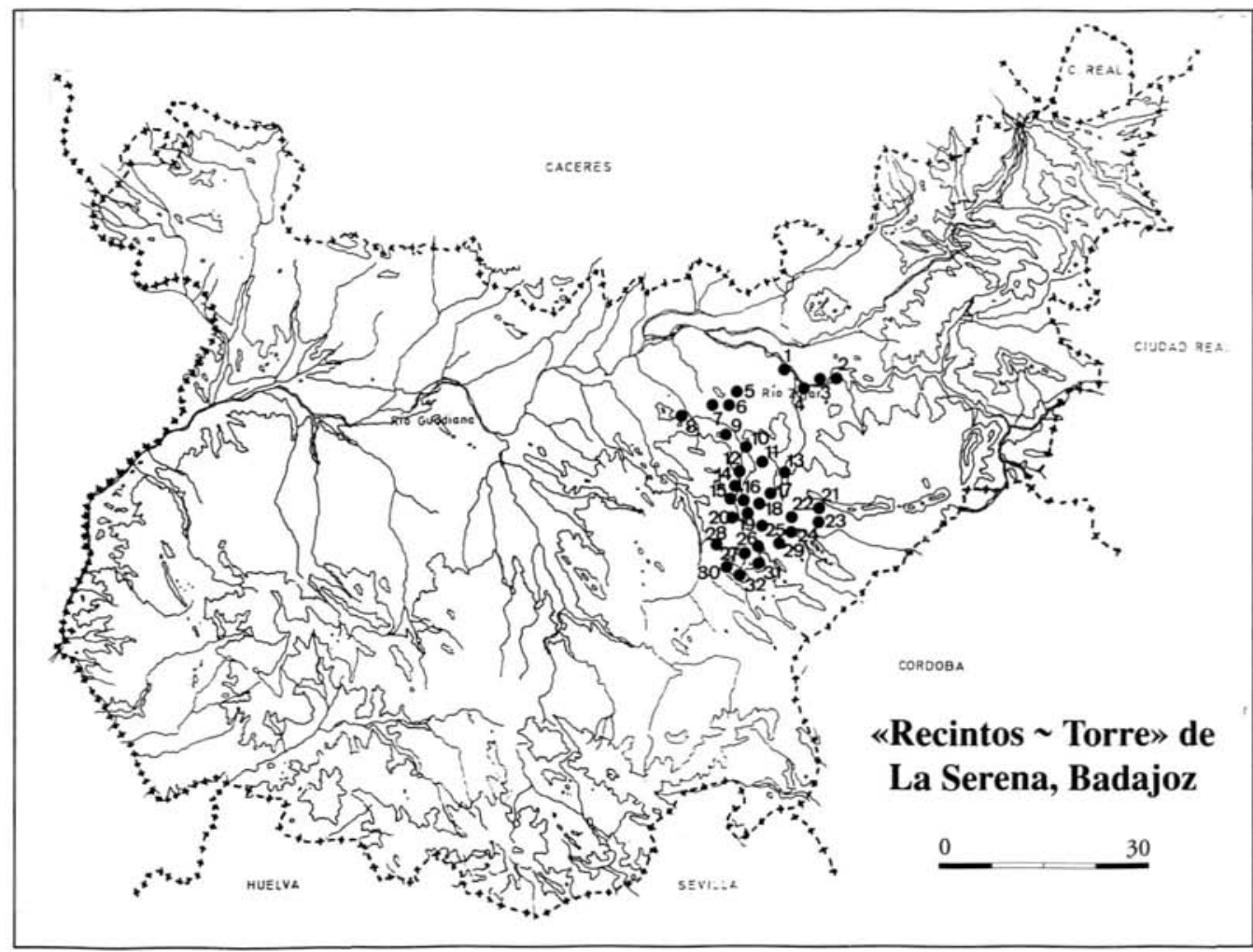

Figura 6. 1, Mingorramos; 2, Embalse del Zújar; 3, Cerro del Tesoro; 4, La Portugalesa; 5, La Torre; 6, Cerro Porra; 7, Torruco; 8, Cabeza Redonda; 9, Moruchas; 10, Cañabandera; 11, Egido del Gravamen; 12. Castillo de Hijovejo; 13, Las Huertas; 14, Castillo de Moros; 15, Hijovejo 2; 16, Dehesilla; 17, Castillo del Equivocao; 18, La Mata; 19, Cancho Roano-2; 20, Cerro del Tesoro; 21, Andaque; 22, La Venta; 23, Chozo Blanco; 24, Torruquillo; 25, Avenoso; 26, Torrecilla; 27, Regertilla; 28, Cerro del Castillo; 29, Dehesa Boyal; 30, Rincón del Porquero-1; 31, Torrucha; 32, Rincón del Porquero-2.

\section{RECINTOS-TORRE: LAS EXCAVACIONES ARQUEOLOGICAS Y SUS RESULTADOS}

Dentro de la diversidad tipológica que muestran las construcciones ciclópeas de La Serena, razones diversas nos han llevado a concentrar, desde hace algunos años, nuestros esfuerzos en el conocimiento de los llamados recintos-torre. Entre dichas razones, se encuentran su importancia numérica, su topografía y valor estratégico en relación con las rutas naturales de la zona y el posible control de los recursos inmediatos.

Desde un principio fuimos conscientes del grado de deterioro que presentaban la gran mayoría de los asentamientos prospectados durante la primera fase de nuestro trabajo (Ortiz Romero, 1985). Esta circunstancia nos obligó, de entrada, a seleccionar aquellos puntos que mayores garantías de éxito pudieran proporcionarnos en la segunda fase de nuestro estudio. Ésta poseía, como objetivo principal, valorar desde el punto de vista estratigráfico unas construcciones que, 
en primera instancia, diferenciaban notablemente esta comarca del núcleo cordobés (Fortea y Bernier, 1970; Serrano Carrillo y otros, 1984). Como podrá comprobarse, el método de excavación elegido ha condicionado en buena medida el grado de aproximación al estudio de las tres variables que consideramos como objetivo final en el conocimiento de estos recintos: función, filiación cultural y cronología. Obviamente, los sondeos estratigráficos practicados en diversos puntos de estos edificios nos han proporcionado una mayor información sobre la cronología y la filiación cultural de los mismos, en detrimento de la función. Ésta, lógicamente, está más en relación con una excavación en extensión de estas construcciones, próxima a emprenderse dentro ya de una tercera fase de nuestro Proyecto.

Con estos planteamientos previos, nuestro interés se centró en el Castillejo de Hijovejo de Quintana de la Serena (Rodríguez Díaz y Ortiz Romero, 1986) (Figs. 7-8), Cancho Roano-2 de Zalamea de la Serena, El Torruquillo, el Castillejo del Equivocao de Castuera y La Portugalesa de Campanario (Ortiz Romero y Rodríguez Díaz, 1988). Dichos trabajos se inscribieron en el Plan de Sondeos Estratigráficos elaborado por la Dirección General de Patrimonio de la Junta de Extremadura entre los años 1986 y 1988.

A pesar de que el estado inicial de la investigación nos obliga en todo momento a ser prudentes en la valoración de estos primeros resultados y a someterlos a una contrastación permanente; en síntesis, podemos señalar que, en función del siempre escaso material recuperado, los recintos-torre de La Serena ofrecen una secuencia estratigráfica, en líneas generales, bastante similar, si bien no puede hablarse de una plena sincronía entre ellos. De cualquier forma, puede afirmarse que la época de máxima actividad de dichas construcciones debe situarse entre el siglo I a. C. y el siglo I d. C., aunque algunas de ellas pudieron tener una fecha inicial algo anterior. El material arqueológico se caracteriza por su uniformidad, resultando prácticamente imposible establecer pautas cronológicas firmes. En conjunto, dichos materiales revelan de forma clara la desintegración y el declive de los tipos que caracterizaron la Segunda Edad del Hierro en esta región (Rodríguez Díaz, 1989) ante la creciente presencia de elementos romanos.

De esta forma, las cerámicas a mano prácticamente han desaparecido siendo sustituidas por las producciones a torno. Estas están representadas por los tipos habituales del tránsito entre la República y el Imperio: paredes finas de pastas anaranjadas y grises y comunes de diverso tipo. Por su parte, las formas ofrecen un amplísimo repertorio, bien documentado por diferentes autores (Mezquiriz Catalán, 1961; Vegas, 1973; Mayet, 1975; Alarçao, 1975; Beltrán Lloris, 1990): ánforas, grandes vasijas de almacén, cazuelas, morteros, cuencos, platos, tapaderas, etc. Asimismo y en proporción variable, resulta frecuente la presencia de materiales de clara filiación indígena, como son las cerámicas grises y las cerámicas de cocción oxidante, lisas y pintadas o pintadas-estampilladas. Respecto a las cerámicas pintadas, señalar que la mayor partê de los motivos decorativos representados son deudores de los geométricos lineales que alcanzaron su máximo desarrollo en los asentamientos protohistóricos del sur peninsular (Escacena Carrasco, 1986; Ruiz Mata, 1987, etc.): bandas paralelas de distinto grosor, círculos y semicírculos concéntricos, etc. Dichos motivos están realizados, en su mayoría, en pintura de calidad variable y color rojo vinoso básicamente, si bien no resultan extrañas algunas asociaciones con el blanco. Por su parte, los motivos estampillados, asociados a veces a la decoración pintada, son muy escasos y nos remiten especialmente a reticulados o rosetas (Almagro Gorbea, 1976-1978; Nieto Gallo y otros, 1980; Vélez Rivas y Pérez Avilés, 1987, etc.). Entre las formas, destacan las urnas de borde exvasado, los cuencos de perfil hemiesférico y los platos de borde saliente. En cualquier caso, resulta evidente que son especies cerámicas en franco retroceso, cuya convivencia con otros materiales de época romana impide elevar su cronología 


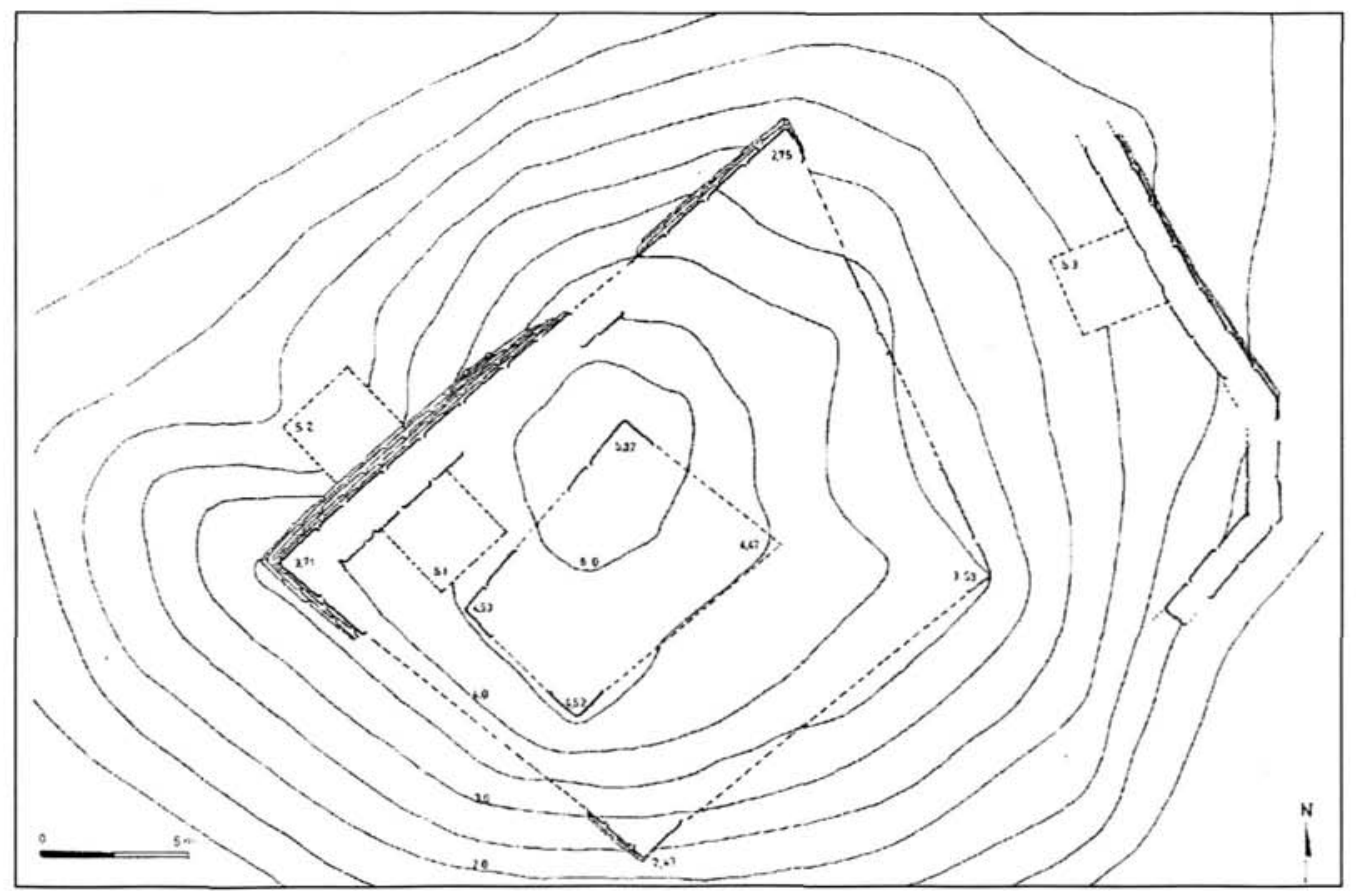

Figura 7.Topografía y planta aproximada del recinto-torre de Hijovejo (Quintana de la Serena)

más allá de comienzos del siglo II a. C. En este sentido, el caso más revelador lo constituye una vez más el Castillejo de Hijovejo (Rodríguez Díaz y Ortiz Romero, 1986) (Figs. 9-10).

$\mathrm{Si}$ la fecha inicial de estas construcciones presenta algunos problemas, debido sobre todo a la escasa potencia estratigráfica que conservan y a lo arrasado de sus estructuras, menos dificultades existen para determinar la naturaleza y la cronología de su abandono definitivo. En virtud de la pobreza de los restos encontrados y ante la ausencia de signos evidentes de violencia, dicho abandono debió tener un carácter pacífico y, cronológicamente, en función de la presencia de sigillata hispánica en los niveles superiores excavados, debió producirse a finales del siglo I d. C., si bien esta datación podría alcanzar los primeros años del siglo II en algún caso.

Si algo se avanza en el conocimiento de la filiación cultural y cronología de estas construcciones, no puede decirse lo mismo en lo referente a su función. Ello lógicamente viene determinado, como señalamos anteriormente, por la metodología de excavación empleada. Sin embargo, no desechamos de entrada las hipótesis que puedan derivarse de una primera aproximación al tema y que futuros trabajos se encargarán de contrastar.

En este sentido, resulta fácil imaginar que la función desempeñada por estas construcciones en la comarca de La Serena debió responder a unos estímulos estrechamente ligados a la explotación y control de los recursos potenciales de dicha comarca. Así, desde de una perspectiva macroespacial, puede apreciarse que estos recintos-torre jalonan las principales rutas naturales que ponen en contacto el Valle Medio del Guadiana con la Meseta Sur y el sector nordoccidental de la provincia de Córdoba. Como quedó reflejado más arriba, una rápida valoración de los recursos de la zona pone de relieve su pobreza agrícola frente a un relativo desarrollo de la gana- 


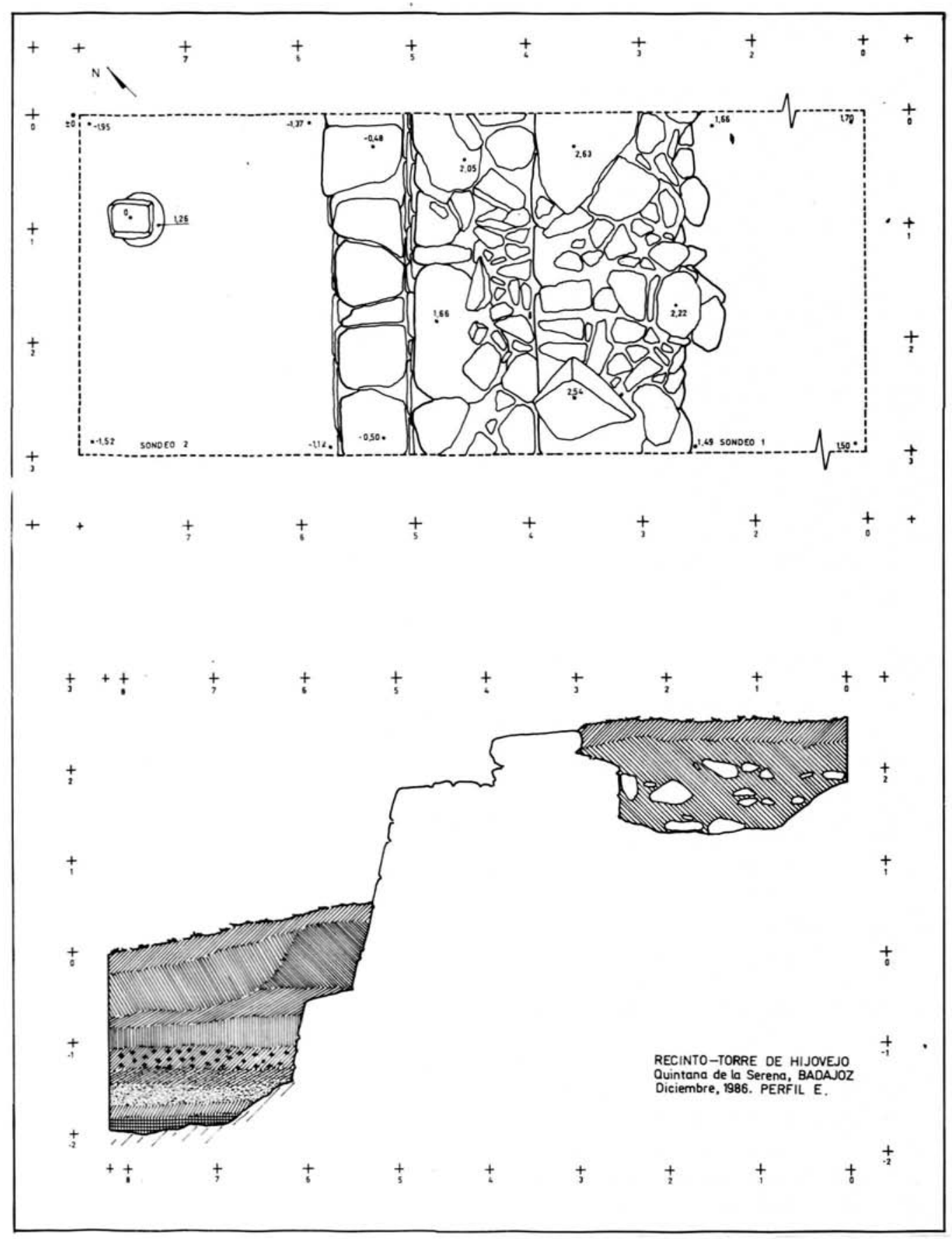

Figura 8. Hijovejo, 1986: planta y perfil de los sondeos 1 y 2. 
dería y a una considerable riqueza del subsuelo. Ésta se concreta en la presencia de importantes filones de galenas argentíferas que, aunque pobres en plata, aportaron entre finales del siglo XIX y la primera mitad del XX importantes cantidades a la producción nacional de plomo (AA.VV., 1987: 112). Muy posiblemente buena parte de estos filones metalíferos debieron ser conocidos y explotados en época antigua, coincidiendo con la puesta en valor de otras zonas próximas como Azuaga (Domergue, 1970) y el noroéste de Córdoba (Domergue, 1985 y 1987). Ni que decir tiene que resulta tentador establecer conexiones entre el máximo desarrollo de estas construcciones y la intensa actividad minero-metaúrgica desarrollada en dichas zonas a partir del siglo I a. C.; una actividad que, como es sabido, se vio en gran medida potenciada a raíz de los conflictos bélicos de finales de la República que tuvieron como escenario el territorio lusitano (Roldán Hervás, 1978; Alvarez Martínez, 1985).

Sin embargo, la pobreza del registro arqueológico nos permite argumentar muy parcialmente estas cuestiones o correlaciones que, por otro lado, parecen tomar mayor consistencia en el sur de Portugal en edificios que presentan claras semejanzas estructurales con los de La Serena (Maia, 1986). En este sentido, en la región extremeña, destacar tan solo la aparición, en uno de los sondeos realizados en La Portugalesa de Campanario, de una torta de fundición de plomo, producto inequívoco del trabajo in situ de este mineral. Asimismo, resulta de interés referir la posible relación con la minería que apuntan asentamientos como los de La Regertilla 1 y 2, en función de los abundantes restos de escorias de fundición de hierro detectados en superficie. En favor también de la importancia alcanzada por la minería del plomo durante estos siglos én el sector oriental de la provincia de Badajoz hablan, aparte de los referidos hallazgos de Azuaga, los numerosos glandes, pesas, ponderales, plomadas, téseras y lingotes de plomo recientemente descubiertos en el poblado de Hornachuelos y sus alrededores (Jiménez Avila, 1990).

A menor escala, una vez más el carácter estratigráfico que ha presidido nuestros trabajos nos ha impedido valorar la organización microespacial de estas construcciones. Nada sabemos de las características de las divisiones internas de estos recintos, aunque restos de superficie y otros encontrados en los sondeos practicados en Cancho Roano-2 y Castillo de Hijovejo confirman su existencia. En este mismo sentido, los últimos trabajos realizados en el Castillo del Equivocao de Castuera evidencian la existencia de viviendas o dependencias de diverso tipo en torno al núcleo central del recinto. No obstante, la escasez de restos arqueológicos recuperados en su interior nuevamente ha impedido determinar la naturaleza de las actividades realizadas en ellas. Lo que sí resulta evidente es que dichas estancias, delimitadas con muros de un espesor medio, se encuentran protegidas por estructuras ciclópeas que a veces superan los $2 \mathrm{~m}$. de anchura. Sobre éstas, los sondeos nos han informado que se superpondrían alzados de adobes, que completarían el paramento exterior, cuya altura total -a juzgar por los restos encontrados- debió girar en tomo a los 3-5 m. Se trata de un sistema constructivo conocido desde antiguo en la propia comarca de La Serena (Maluquer de Motes, 1981 y 1983) y que se ha mantenido a lo largo de los siglos hasta nuestros días. Finalmente, señalar en relación a las cubiertas de estos edificios que, salvo contados fragmentos de tégulas, no hay indicios claros de su naturaleza. En este sentido, no descartamos las soluciones de entramados vegetales y terrazas, propuestas para los recintos portugueses (Maia, 1986: 207-208).

En su conjunto, estos núcleos debieron mostrar un aspecto de pseudofortaleza, aunque sin llegar a serlo plenamente debido al carácter abierto y desprotegido de los lugares en que se localizan. No obstante, sería el ya referido ambiente general de inestabilidad social que caracterizó el período inmediato al cambio de Era lo que podría haber motivado, a nuestro entender, el carác- 


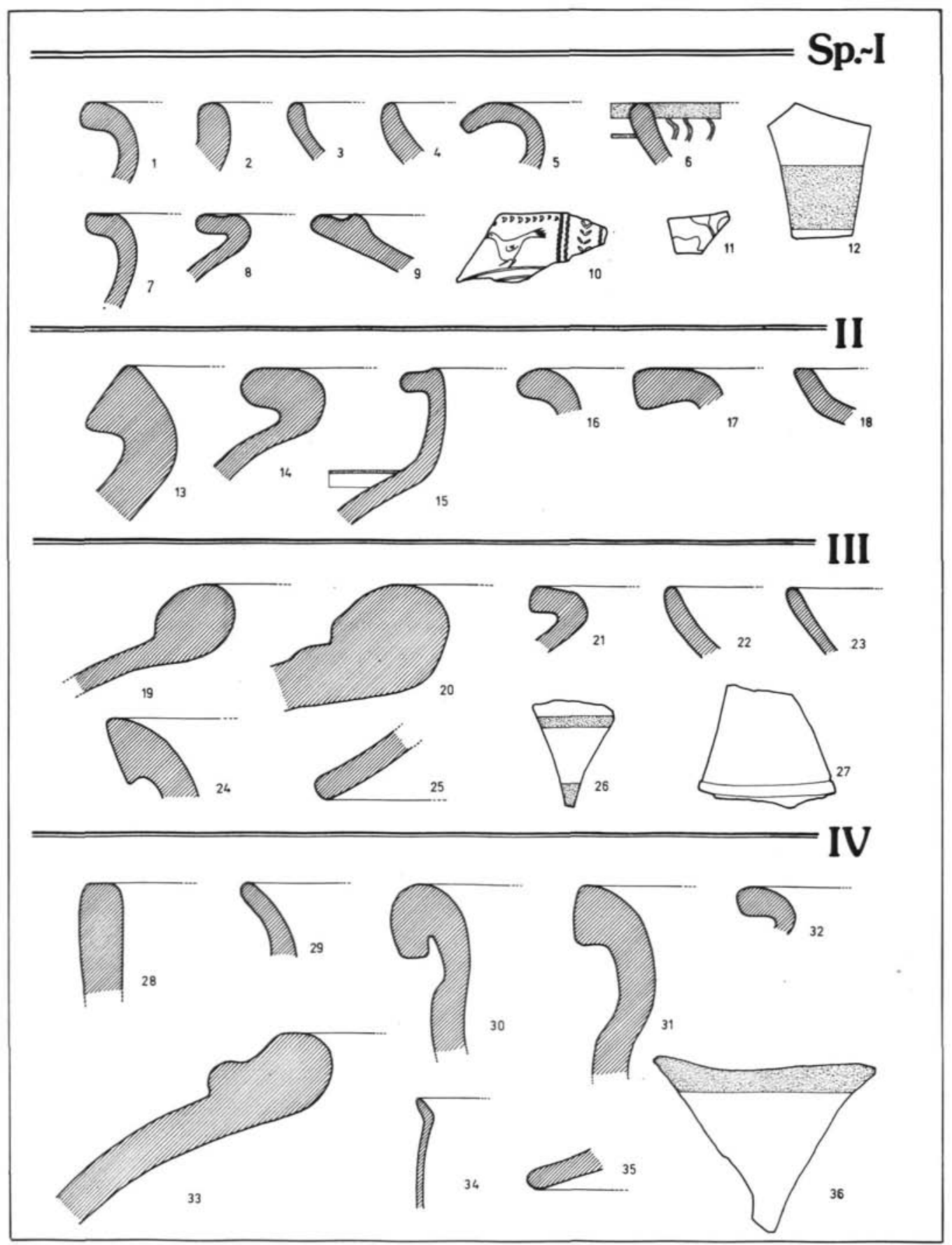

Figura 9. Hijovejo, 1986. Sondeo 1: materiales cerámicos niveles Sp-IV. 


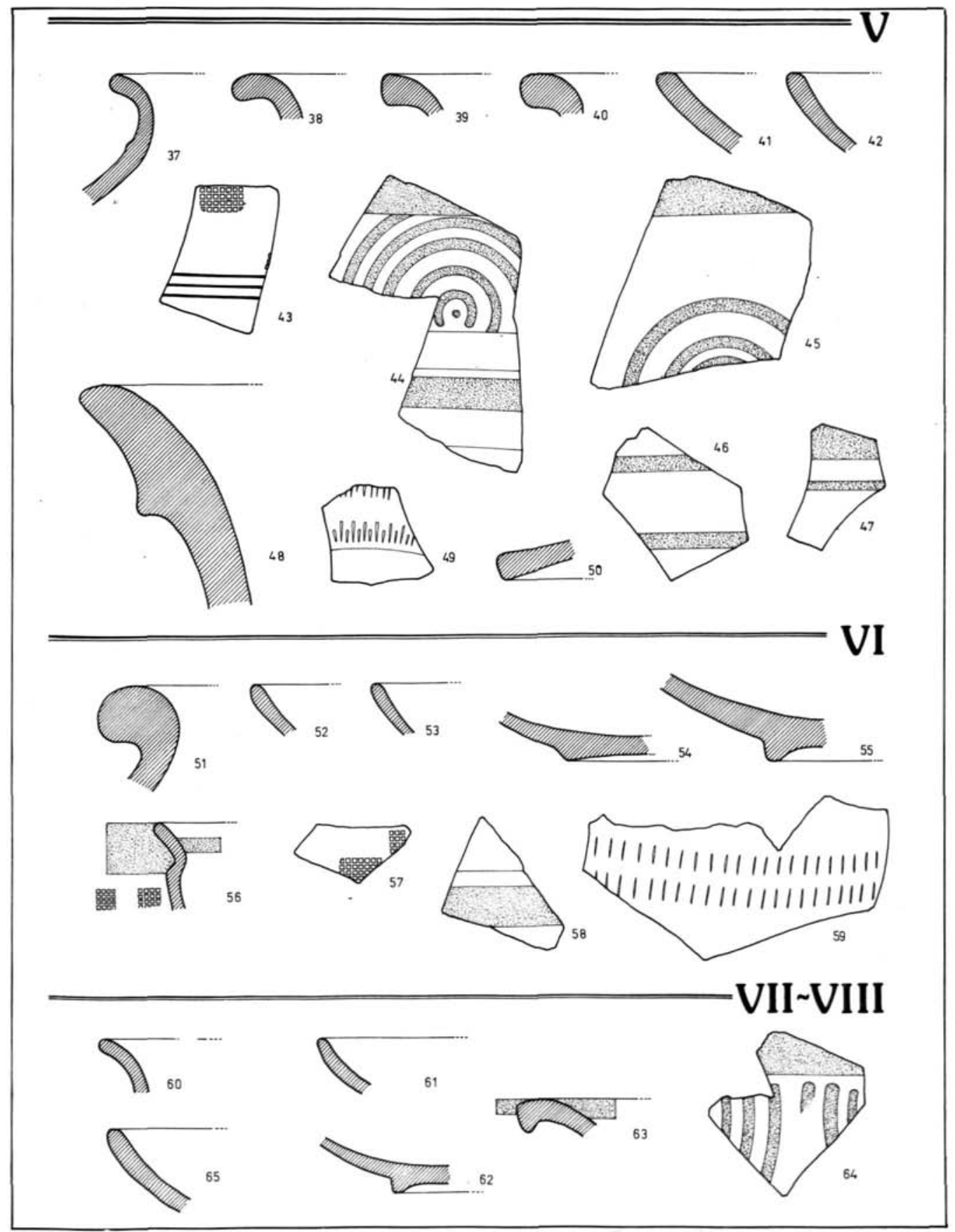

Figura 10. Hijovejo, 1986. Sondeo 1: materiales cerámicos niveles V-VIII. 
ter cuasi defensivo que presentan estas construcciones, si bien este hecho también podría deberse simplemente al mantenimiento de un sistema de construcción tradicional. Sea como fuere, todo parece indicar que en estas construcciones se conjugan una serie de aspectos sociales y económicos cuya naturaleza y entidad aún estamos lejos de determinar en su plenitud.

\section{CONSIDERACIONES FINALES}

A pesar de encontrarnos actualmente en una fase inicial de la investigación de la protohistoria reciente de la Baja Extremadura, consideramos de gran interés la diversidad tipológica y cultural que ofrece el poblamiento de nuestra región en los últimos siglos del Ier milenio a. C. Una diversidad surgida, entre otras cosas, precisamente de la valoración del heterogéneo conjunto de asentamientos como el que nos muestra la comarca de La Serena. El estudio particular de los recintos ciclópeos nos ha obligado a diseñar unas líneas de investigación que, sin perder de vista el marco general, se centran en la consideración de las particularidades que dichas construcciones puedan ofrecer respecto a otras zonas peninsulares en relación a su función, filiación cultural y cronología.

Dentro del grupo de construcciones ciclópeas extremeñas, aún es demasiado pronto para valorar estas cuestiones de una forma interrelacionada entre los diversos subtipos establecidos: fortificaciones, recintos de altura y recintos-torre. Como hemos podidos comprobar, los mayores progresos se han producido en el grupo de los recintos-torre. Merced a los sondeos estratigráficos practicados en aquellos lugares mejor conservados, algo hemos podido avanzar en el conocimiento de su cronología y filiación cultural. En este sentido, todo parece indicar que estos edificios, ubicados en el llano de La Serena, conocieron sus momentos de mayor actividad entre el siglo I a. C. y el siglo I d. C., si bien dichas fechas admiten una cierta flexibilidad en sus límites. Se trata de un momento en el que en nuestra región se asiste al abandono de algunos poblados indígenas (otros alcanzarán, por el contrario, un gran desarrollo) y la ocupación sistemática del llano por parte de los romanos. Sin duda, es un período para la Península Ibérica de intensos acontecimientos sociopolíticos, algunos de los cuales adquieren una especial relevancia en el actual territorio extremeño. No obstante, debido a la imprecisión cronológica en la que nos movemos, consideramos tremendamente arriesgado asociar de forma rígida estas construcciones a una situación histórica concreta.

Pero, indudablemente, muchos más problemas presenta la determinación de la función desempeñada por estas construcciones en La Serena. En buena lógica, su diversidad debe obedecer igualmente a una diversidad funcional. De este modo, si el carácter estratégico y defensivo de las fortificaciones y recintos de altura resulta bastante claro, menos evidente se nos muestra el papel desempeñado por los recintos del llano. En esta línea, como hemos apuntado, son muy tentadoras las enormes posibilidades mineras que ofrece el subsuelo de La Serena, si se valoran en relación con el gran desarrollo que conocen estas actividades en zonas tan próximas como Azuaga, Hornachos y Ribera del Fresno (Badajoz) y el noroeste cordobés. No obstante, no contamos con las evidencias arqueológicas suficientes en La Serena para confirmar una plena correspondencia o, al menos relación, entre las torres y los filones metalíferos, si bien existen algunos indicios al respecto.

De cualquier forma, cabe resaltar que, a pesar de sus limitaciones, los resultados obtenidos en esta comarca extremeña ponen de manifiesto suficientemente las peculiaridades que la definen y distinguen culturalmente de otras áreas peninsulares donde se conocen con anterioridad manifestaciones similares. 


\section{BIBLIOGRAFIA}

AA. VV. 1968: Explicación del Mapa Provincial de Suelos, Madrid.

... 1987: La mineria en Extremadura., Mérida.

AlARÇAO, J. 1975: Fouilles de Conimbriga, V. La céramique comunne locale et regionale. París.

ALmAGRO BASCH, M. 1966: Las estelas decoradas del Suroeste peninsular. BPH.,VIII. Madrid.

Almagro Gorbea, M. 1976-78: "La iberización de la zona oriental de la Meseta", Ampurias, 38-40. 93-156.

... 1977: El Bronce Final y el Periodo Orientalizante en Extremadura, BPH., XIV. Madrid.

Almagro Gorbea, M. y Del Amo, M. 1985: "Bronces ibéricos en Extremadura”, Homenaje a Cánovas Pesini, Badajoz, 71-83.

Almagro Gorbea, M. y Lorrio Alvarado, L. A. 1986: "El castro de Entrerríos (Badajoz)". Rev. de Estudios Extremeños, XLII-III. 617-631.

... 1987: "La expansión céltica en la Península Ibérica: una aproximación cartográfica", I Simposium sobre Celtiberos, Zaragoza, 1986.105-122.

Alvarez Martinez, J. M. 1985: "El tiempo antiguo", Historia de Extremadura, 1, Badajoz, 101-180.

Alvarez MuÑoz, E. 1983: Geología de La Serena, Una aproximación a su estratigrafia y a su tectónica, Badajoz.

ARTEAGA, O. 1987: "Excavaciones arqueológicas sistemáticas en el Cerro de los Alcores (Porcuna, Jaén), Informe preliminar sobre la campaña de 1985", Anuario Arqueológico de Andalucia 1985. Sevilla. 279-288.

Barcelo, J. A. 1989: "Las estelas decoradas del Sudoeste de la Península Ibérica”, Tartessos, Barcelona. 189-208.

BELTRAN LlORIS, M. 1990: Guia de la cerámica romana, Zaragoza.

Bendala Galan, M. 1977: "Notas sobre las estelas decoradas del Suroeste y los orígenes de Tartessos", Habis, 8. 177-206.

Blasco Bosqued, C. y Alonso Sanchez, M. A. 1985: "Cerro Redondo, Fuente el Saz del Jarama, Madrid”. EAE., 143.

Bueno Ramirez, P. y otros 1984: "Tres nuevas estelas del Suroeste", Rev. de Estudios Extremeños, XL-III. 477-483.

Celestino Perez, S. 1985: "Los carros y las estelas decoradas del Suroeste", Homenaje a Cánovas Pesini, Badajoz. 45-55.

... 1990: "Las estelas decoradas del Suroeste peninsular", La Cultura Tartésica y Extremadura. Mérida. 45-62.

CUADRADO DiAZ, E. 1957: "La fíbula anular hispánica y sus problemas", Zephyrus, Vlll-1, 5-76.

Domergue, C. 1970: “Un témoignagne sur l'industrie minière et métallurgique du plomb dans la région d'Azuaga (Badajoz) pendant la guerre de Sertorius". XIX CNA, 608-625.

... 1985: "Algunos aspectos de la explotación de las minas de la Hispania en la época republicana". Pyrenae. Crónica Arqueológica. 91-96.

... 1987: Catalogue des mines et de fonderies antiques de la Péninsule Ibérique. Série Archéologique, VIII, Madrid, 2 vols.

ENRIQUeZ NAVASCUES, J. J. 1982: "Dos nuevas estelas de guerreros del Museo Arqueológico Provincial de Badajoz", Museos, 1, 65 y ss.

Enriquez Navascues, J. J. Y Celestino Perez, S. 1981-82: "La estela de Capilla (Badajoz)", Pyrenae, 17-18, 203 y ss. 
... 1984: "Nuevas estelas decoradas de la Cuenca del Guadiana", TP, 41. 237-250.

Escacena Carrasco, J. L. 1986: Cerámicas a torno pintadas andaluzas de la Segunda Edad del Hierro. Tesis Doctoral, Ed. microfichada, Sevilla.

FERnANDEZ Aviles, A. 1958: "De orfebrería antigua hispana. Joyas de plata del Museo de Badajoz". RABM, LXV, 565-578.

FORTEA, J. y BERNIER, J. 1970: Recintos y fortificaciones ibéricos de la Bética, Salamanca.

GarCia y Bellido, A. 1945: España y los españoles hace dos mil años, según la Geografía de Strabón, Madrid (1986).

... 1947: La España del siglo I de nuestra Era (según P. Mela y C. Plinio), Madrid (1982).

Garcia Galan, A. 1984: "Hallazgo de una lápida mortuoria en Las Yuntas (Capilla)", Rev. de Estudios Extremeños, XL-II, 355-358.

Gil. Mascarell Bosca, M. 1971: Yacimientos ibéricos en la Región Valenciana. Estudio del poblamiento, Resumen Tesis Doctoral, Valencia.

Garcia Iglesias, L. 1971: "La Beturia, un problema geografico de la Hispania Antigua". AEA, 44, 86-108.

GUERRA, A.: 1972: "La minería en Extremadura en los siglos XVI, XVII y XVIII", Rev. de Estudios Extremeños, XXVIII, 425-440.

... 1975: "La minería en la Baja Extremadura en la primera mitad del siglo XIX", Rev. de Estudios Extremeños, XXXI, 213-240.

Hernando Fernandez, D. 1971: Estudio de los suelos de Badajoz. Región de La Serena, Madrid.

Jimenez Avila, F. J. 1990: Estudio arqueológico del poblado de Hornachuelos (Ribera del Fresno, Badajoz) y su entorno, Memoria de Licenciatura, Inédita, Cáceres.

Jimenez Navarro, E. y otros 1950: “Arqueología de Magacela”, Rev. de Estudios Extremeños, III-IV, 657-672.

MaiA, M. 1986: "Os "castella" do sul de Portugal", $M M, 27,195-223$.

Maluquer de Motes, J. 1981: "El Santuario protohistórico de Zalamea de la Serena (Badajoz)”. Andalucia y Extremadura, PIP, Barcelona, 225-409.

... 1983: El Santuario protohistórico de Zalamea de la Serena (Badajoz). II, 1981-1982, PIP. Barcelona.

MAluQUer de Motes, J. y otros 1986: El Santuario protohistórico de Zalamea de la Serena, Badajoz, III, 1983-1986, Barcelona.

MAYET, F. 1975: La céramique à parois fines dans la Péninsule Ibérique, Paris.

MeZquiriz Catalan, M. A. 1961: Terra sigillata hispánica, Valencia.

Nieto Gallo, G. y otros. 1980: “Oreto I", EAE., 114. 1980.

Olmos Romera, R. 1978: "El Sileno Simposiasta de Capilla", TP., 34, 371-388.

Ortiz Romero, P. 1985: Carta Arqueológica de La Serena. Hojas del MTN. de Castuera y Zalamea de la Serena, Memoria de Licenciatura, Inédita, Cáceres.

... 1986: Introducción a una historia de la Arqueología en Extremadura, Cáceres.

... 1990: "La secuencia prerromana de La Serena: fortificaciones", Rev. de Estudios Comarcales, 2, 57-70.

Ortiz Romero, P. y Rodriguez Diaz, A.: 1988: "Sondeos estratigráficos en los recintos-torre de la comarca de La Serena (Badajoz)”, Extremadura Arqueológica, 2. (E.p.)

... 1989: "Problemática general en torno a los recintos-torre de La Serena, Badajoz", XIX CNA, Castellón, 1987.

Rodriguez DiAZ, A. 1987: El poblamiento prerromano en la Baja Extremadura, Tesis Doctoral, Inédita, Cáceres. 
... 1989: "La Segunda Edad del Hierro en la Baja Extremadura: problemática y perspecti vas en torno al poblamiento”, Saguntum, 22, 86-108.

... 1990: "Continuidad y ruptura cultural durante la Segunda Edad del Hierro en Extremadura", La Cultura Tartésica y Extremadura, Mérida. 127-162.

Rodriguez Diaz, A. y Jimenez Avila, F. J. 1987-88: "Informe sobre las exavaciones realizadasen ele yacimiento de Hornachuelos, Ribera del Fresno (Badajoz). 1986-1988”, Norba, 8-9, 13-31.

Rodriguez Diaz, A. y Ortiz Romero, P. 1986: "Avance de la primera campaña de excavación en el recinto-torre de Hijovejo (Quintana de la Serena, Badajoz). El sondeo núm. 2”, Norba, 7, 25-1.

Roldan Hervas, J. M. 1978: “La guerra civil entre Sertorio, Metelo y Pompeyo (82-72 a. C.)". En Blazquez Martinez, J. M. y otros: Historia de Hispania Antigua. II Hispania Romana, Madrid, 113-140.

Ruiz MATA, D. 1987: "La formación de la cultura turdetana en la Bahía de Cádiz a través del Castillo de Doña Blanca”, Iberos. I Jornadas sobre el Mundo Ibérico, Jaén, 1985. 299-314.

Ruiz Rodriguez, A. 1978: "Los pueblos iberos del Alto Guadalquivir. Análisis de un proceso de transición”, CPUG, 3, 1978: 255-284.

Ruiz Rodriguez, A. y otros. 1984: "Poblamiento ibérico en la Campiña de Jaén. Análisis de una ordenación del territorio”, I Jornadas de Metodologia e Investigación Prehistórica, Soria, 1981, 421-429.

... 1987: "El poblamiento ibérico en el Alto Guadalquivir", Iberos. I Jornadas sobre el Mundo Ibérico, Jaén, $1985,239-256$.

Serrano Carrillo, J. y otros. 1984: Arqueologia inédita de Córdoba y Jaén, Córdoba.

SOMOZA DE LA PENAA, B. 1875: Opúsculo geógrafo-topográfico-geológico-minero-histórico de una parte de la provincia de Badajoz, con una rápida ojeada a la minería española, Madrid.

Suarez de Venegas Sanz, J. 1986: Carta Arqueológica de las Vegas Altas del Guadiana, Memoria de Licenciatura, Inédita, Cáceres.

... 1990: "Organización territorial de la Extremadura Central. Epoca prerromana", Rev. de Estudios Comarcales, 2,.71-84.

Teran, M. de y Sole Sabaris, L. (dirs.) 1968: Geografiá Regional de España, Barcelona. (1978). la.

VAQUeRIzo GIL, D. 1984: Poblamiento indigena y Romanización de la Siberia Extremeña., Memoria de Licenciatura, Inédita, Córdoba.

... 1986: "Indigenismo y Romanización”, Rev. Arqueología, 58, 10-18.

VEGAS, M. 1973: Cerámica común romana del Mediterráneo Occidental, Barcelona.

Velez Rivas, J. y Perez Aviles, J. J. 1987: "El yacimiento protohistórico del Cerro de las Cabezas (Valdepeñas)", Oretum, I, 168-196. 